Tropical Journal of Pharmaceutical Research November 2016; 15 (11): 2429-2434

ISSN: $1596-5996$ (print); 1596-9827 (electronic)

(C) Pharmacotherapy Group, Faculty of Pharmacy, University of Benin, Benin City, 300001 Nigeria.

All rights reserved.

Available online at http://www.tjpr.org

Original Research Article

http://dx.doi.org/10.4314/tjpr.v15i11.18

\title{
Comparison of the acute effects of Tulbaghia violacea William Henry Harvey (Alliaceae) on blood pressure and heart rate of ageing male normotensive Wistar kyoto rats and adult male spontaneously hypertensive rats
}

\author{
Ismaila Raji ${ }^{1}$, Kenechukwu Obikeze ${ }^{2}$, Pierre Mugabo ${ }^{2}$ \\ ${ }^{1}$ Faculty of Medicine, National University of Science and Technology, Zimbabwe, ${ }^{2}$ School of Pharmacy, University of the \\ Western Cape, South Africa
}

*For correspondence: Email: ismailaraji@gmail.com Tel: +263 9 203336/7/8

Received: 2 June 2016

Revised accepted: 20 October 2016

\begin{abstract}
Purpose: To assess the effect of the crude methanol leaf extracts of Tulbaghia violacea William Henry Harvey (Alliaceae) on blood pressure $(B P)$ and heart rate in ageing normotensive Wistar Kyoto rats (WKY), and compare the results obtained with those for adult spontaneously hypertensive rats (SHR). Methods: T. violacea $(5-150 \mathrm{mg} / \mathrm{kg}$ ) and/or vehicle (dimethylsulfoxide and normal saline) were respectively and randomly administered intravenously to groups of ageing (15 months) WKY and adult (<5 months) SHR, weighing 380 - 470 and 280 - $320 \mathrm{~g}$, respectively. BP and heart rate (HR) were measured via a pressure transducer connecting the femoral artery and Powerlab equipment.

Results: $T$. violacea significantly and dose-dependently reduced systolic $B P$, diastolic $B P$, mean arterial pressure (MAP) and HR in both strains of rats. No statistically significant differences were however observed when the changes in BP and HR in the two rats strains were compared.

Conclusion: $T$. violacea was effective in reducing BP and HR in both age-induced and spontaneously hypertensive rats.
\end{abstract}

Keywords: Age, Wistar Kyoto rats, blood pressure, heart rate, Tulbaghia violacea

Tropical Journal of Pharmaceutical Research is indexed by Science Citation Index (SciSearch), Scopus, International Pharmaceutical Abstract, Chemical Abstracts, Embase, Index Copernicus, EBSCO, African Index Medicus, JournalSeek, Journal Citation Reports/Science Edition, Directory of Open Access Journals (DOAJ), African Journal Online, Bioline International, Open-J-Gate and Pharmacy Abstracts

\section{INTRODUCTION}

Treatment of hypertension (HTN) has been one of the major successes of medicine in the past half-century [1,2]. However, the number of people with uncontrolled blood pressure is increasing, despite therapeutic advances [3]. Consequently, the prevalence of HTN is still on the rise in developing countries [4] and worldwide [3]. As a result of better management of both communicable and non-communicable diseases, the global population of the elderly is increasing, a trend that has been predicted to continue in the coming decades $[3,5]$. Therefore, the incidence and prevalence of HTN, as well as clinical and subclinical cardiovascular disease (CVD) in general, are expected to rise [3]. Hypertension is associated with considerable morbidity and an increased risk of CVD, stroke, decreased quality of life, and mortality in the elderly [1-3]. Furthermore, ageing and HTN play critical roles in both cardiovascular (CV) and cerebrovascular complications $[2,3]$.

Tulbaghia violacea Harv. (Alliaceae) is common throughout Africa, with the highest concentration 
in Southern Africa, where it is widely used as herbal remedy for various complaints, including HTN [6,7]. T. violacea has been suggested to have similar secondary metabolites and biological activities as garlic since they belong to the same plant family [6,7], and for these reasons, there has been a recent increase in the number of studies aimed at exploring and/ or confirming the therapeutic potential of $T$. violacea on the CV system [8-12].

The direct and indirect costs of HTN are high $[4,13]$, and the incidence of HTN is relatively high among the elderly. Also, the elderly are largely excluded from many clinical trials, as they belong to the upper age limits and/or do not present with age-specific results $[5,14]$. A couple of studies have investigated the effect of $T$. violacea on different strains of rats, including the adult Wistar rats [9], the spontaneously hypertensive rat (SHR) [11,12] and the Dahl salt-sensitive rats (DSS) $[8,10,15]$. The inhibition of the angiotensin converting enzyme (ACE) [9,11] and the $\beta 1$ adrenoceptors [12]; the reduction in the expression of angiotensin II type 1a (AT1a) mRNA [8], and levels of aldosterone in plasma [12]; and increases in diuresis and natriuresis $[8,10]$ are some of the mechanisms that have been suggested to elicit the effects observed.

Therefore, the present study assessed the effect of the crude methanol leaf extracts of $T$. violacea on blood pressure (BP) and heart rate in ageing normotensive Wistar Kyoto rats (WKY), and compared the results obtained with those of adult SHR.

\section{EXPERIMENTAL}

\section{Plant material}

Fresh plants were purchased from the New Plant Nursery, George, South Africa in August and September, 2008; identified by a taxonomist at the University of the Western Cape (UWC), Bellville; and deposited at the herbarium at the UWC, with voucher numbers 6955 and 6956.

\section{Plant extraction}

To obtain the crude methanol leaf extract (MLE) of the plant, $2.4 \mathrm{~kg}$ of fresh plants were weighed, oven-dried, boiled in methanol in the Soxhlet apparatus. Excess solvent was removed from the resulting extract with a rotavapor and freezedrying, and the direct extract stored in a brown bottle in a $-4{ }^{\circ} \mathrm{C}$ freezer. The final dried extract was $76.6 \mathrm{~g}$ or $3.2 \%$ of the original weight of the fresh plant [12].

\section{Animals}

Healthy male WKY and SHR were obtained from the Animal Unit of the University of Cape Town, South Africa. The WKY weighed 380 - $470 \mathrm{~g}$ and aged just over 15 months, while the SHR weighed 280 - $320 \mathrm{~g}$ and aged less than 5 months. All rats were kept in the Animal house, School of Pharmacy, University of the Western Cape; and given water and normal rat pellet ad libitum. The room temperature was kept at $24^{\circ} \mathrm{C}$, with a 12:12 h light-dark cycle. From literature, the median lifespan of the WKY is 21.5 months $[16,17]$. Therefore, 15 month old WKY were used in the present study. This is an age that is slightly older than those stated for aging groups in literature $[18,19]$.

\section{Drugs}

Drops of dimethylsulfoxide (Merck Chemicals, South Africa) were used to dissolve $T$. violacea, and the resultant paste made up to the required dilution using $0.9 \%$ saline.

\section{In vivo experiments}

The effects of different doses of the methanol leaf extracts (MLE) of $T$. violacea $(5-150 \mathrm{mg} / \mathrm{kg}$ ) on both anaesthetized WKY and SH rats were determined using the method previously described [12]. The femoral artery of the rats were cannulated to measure $B P$ and $H R$, while the jugular vein were cannulated for intravenous infusion of $T$. violacea. The randomized doseresponse experiments (DRE) for MLE of $T$. violacea (5-150 $\mathrm{mg} / \mathrm{kg}$ ) were carried out using 8 WKY and $8 \mathrm{SH}$ rats for each dose of extract.

\section{Data analysis}

The paired and/or unpaired Student's T test was used to calculate statistical significance $(p<$ $0.05)$ between values obtained at baseline with that obtained after infusing the dose of the extract. It was also used to compare the changes in BP and/or HR observed in the WKY with those obtained in the SHR.

\section{Ethical considerations}

The methodology and ethics adhered to in this study were approved by the Ethics Committee of the University of the Western Cape, with a registration number of 09/7/35. All experimental procedures used in the study were conducted in accordance with the guidelines provided by the European Community guidelines (EEC Directive of 1986; 86/609/EEC). 


\section{RESULTS}

The ageing WKY rats used in this study had a body weight ranging from $380-470 \mathrm{~g}$ and were over 15 months old. In the WKY, T. violacea (150 $\mathrm{mg} / \mathrm{kg})$ significantly $(p<0.05)$ and dose dependently decreased SBP, DBP and MAP values $(66.83 \pm 10.84,31.33 \pm 7.79$ and $44.00 \pm$ $8.48 \mathrm{mmHg}$ respectively; when compared to their respective values at baseline (139.25 \pm 8.71 , $95.00 \pm 6.81$ and $110.38 \pm 7.44 \mathrm{mmHg}$ ) (Figures 1 to 3 ). This equates to $54.73 \pm 4.36 \%, 69.83 \pm$ $7.79 \%$ and $63.04 \pm 6.05 \%$ reduction in SBP, DBP and MAP respectively with the highest dose (Table 1). $\quad T$. violacea $(150 \mathrm{mg} / \mathrm{kg})$ also significantly $(p<0.05)$ and dose -dependently decreased HR values obtained $(250.00 \pm 9.81$ bpm) when compared to the value at baseline $(379.38 \pm 8.03 \mathrm{bpm})$ (Figure 4), i.e, a $33.72 \pm$ $1.03 \%$ reduction in HR with the highest dose (Table 1).
In the SHR, $T$. violacea $(150 \mathrm{mg} / \mathrm{kg})$ significantly $(p<0.05)$ and dose-dependently decreased the SBP, DBP and MAP values obtained (117.96 \pm $7.98,73.06 \pm 7.18$ and $88.14 \pm 7.17 \mathrm{mmHg}$ respectively) when compared to their respective values at baseline $(199.97 \pm 5.17,147.68 \pm 4.63$ and $165.30 \pm 4.55 \mathrm{mmHg}$ ) (Figures 1 to 3 ). This equates to $42.38 \pm 3.68 \%, 51.67 \pm 4.33 \%$ and $47.91 \pm 3.82 \%$ reduction in SBP, DBP and MAP respectively at the highest dose (Table 1$)$. $T$. violacea $(150 \mathrm{mg} / \mathrm{kg})$ also significantly $(p<0.05)$ and dose-dependently decreased HR values obtained (309.71 $\pm 20.15 \mathrm{bpm})$ when compared to the value at baseline $(389.44 \pm 17.31 \mathrm{bpm})$ (Figure 4), i.e, a $20.82 \pm 1.96 \%$ reduction in HR at the highest dose (Table 1).

The percentage changes $(\% \Delta)$ in $\mathrm{BP}$ and $\mathrm{HR}$ observed at the different MLE doses were similar between the two rat strains (Figures 1 to 4).

Table 1: Baseline biologic parameters in WKY and SHR

\begin{tabular}{lllllll}
\hline & AGE & WEIGHT & SBP & DBP & MAP & HR \\
\cline { 2 - 7 } & $\mathbf{M}$ & $\mathbf{g}$ & $\mathbf{m m H g}$ & & & bpm \\
\hline WKY & 15 & $421.6 \pm 14.9$ & $139.3 \pm 8.7$ & $95.0 \pm 6.8$ & $110.4 \pm 7.4$ & $379.4 \pm 8.0$ \\
\hline SHR & 5 & $317.9 \pm 4.4^{*}$ & $200.0 \pm 5.2^{*}$ & $147.7 \pm 4.6^{*}$ & $165.3 \pm 4.6^{*}$ & $389.4 \pm 17.3$ \\
\hline
\end{tabular}

* Statistical significance. $\mathrm{m}=$ months. $\mathrm{g}=$ grams. bpm $=$ beats per minute
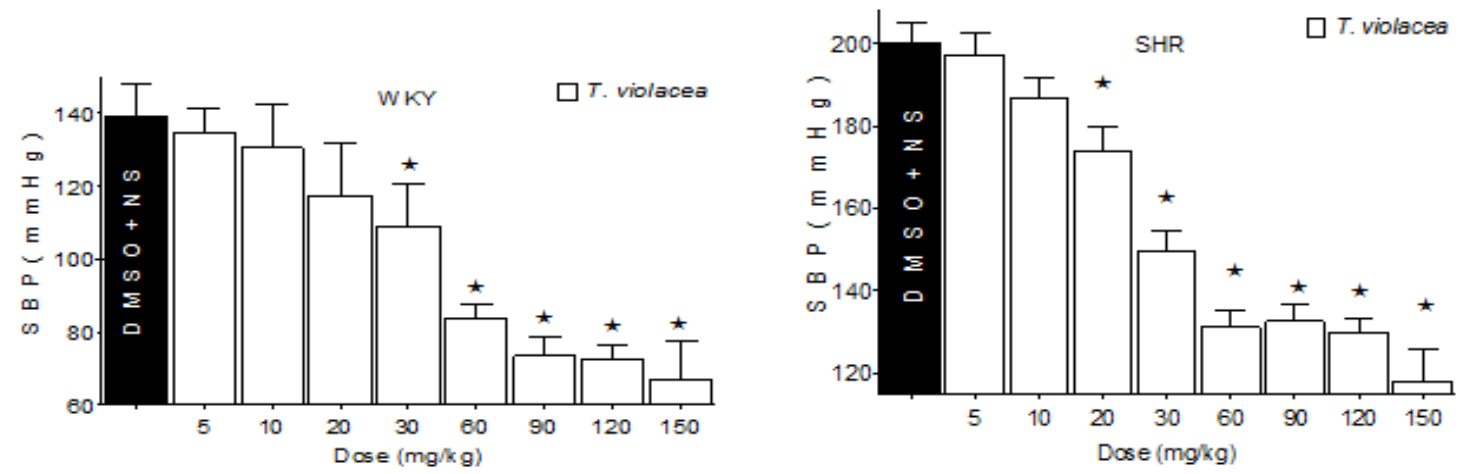

Figure 1: Effect of T. violacea ( $5-150 \mathrm{mg} / \mathrm{kg}$ ) on SBP in WKY and SHR. Values are presented as mean \pm SEM.

^ indicates statistical significance
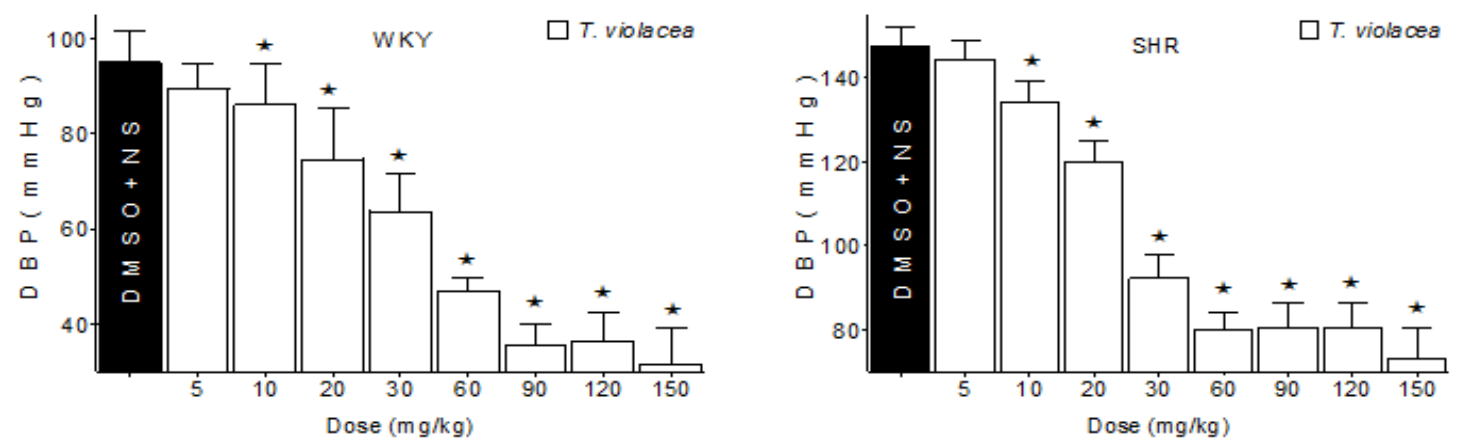

Figure 2: Effect of $T$. violacea $(5-150 \mathrm{mg} / \mathrm{kg})$ on DBP in WKY and SHR. Values are presented as mean \pm SEM. ^ indicates statistical significance 

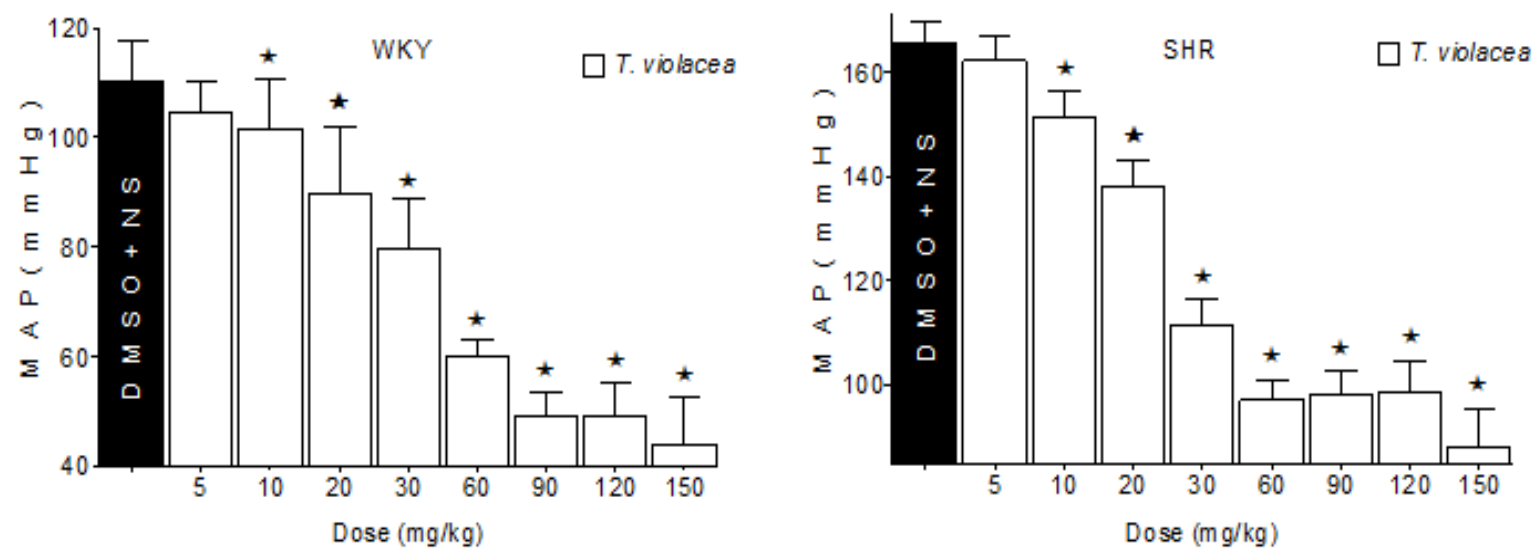

Figure 3: Effect of $T$. violacea (5 $-150 \mathrm{mg} / \mathrm{kg}$ ) on MAP in WKY and SHR. Values are presented as mean \pm SEM. ^ indicates statistical significance
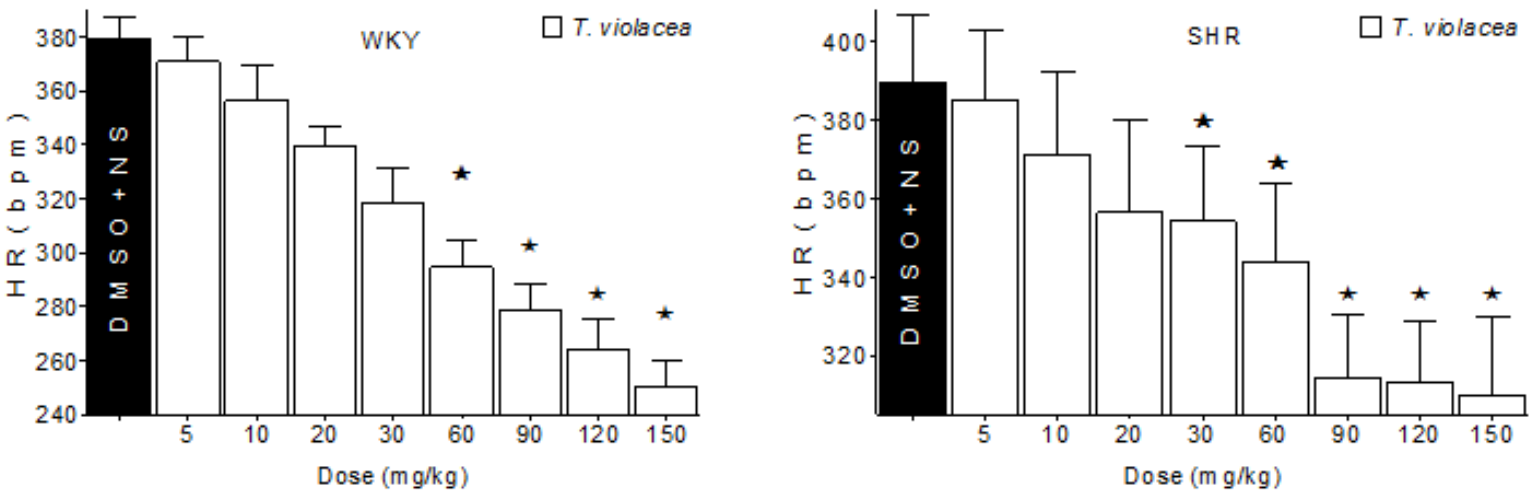

Figure 4: Effect of T. violacea (5 - $150 \mathrm{mg} / \mathrm{kg}$ ) on HR in WKY and SHR. Values are presented as mean $\pm \mathrm{SEM}$; indicates statistical significance $(p<0.05)$

\section{DISCUSSION}

The age of the WKY rats (15 months) used in this study is equivalent to 45 years and above in humans [20,21]. The difference in basal HR between the ageing WKY and the adult SHR was not significant. However, the ageing WKY had significantly lower BP, and significantly higher body weight as compared to the adult SHR. The baseline SBP of the ageing rats used in this study was significantly higher than the normal value of $120 \pm 14 \mathrm{mmHg}$ as seen in adult (5 months) normotensive rats, while the SBP of the SHR used in the study was also higher than the normal value for normotensive rats, but within the normal range for hypertensive rats $[17,22]$.

Rats of different strains and age were used in the study to compare the effect of the crude MLE of $T$. violacea on old age - related increase in BP, with spontaneous HTN [19,23]. T. violacea significantly and dose-dependently reduced the SBP, DBP, MAP and HR in both WKY (Figure 1) and SHR (Figure 2), with the percentage changes $(\% \Delta)$ in both BP and HR being similar between the two strains of. The results obtained in the ageing WKY is consistent with that obtained by Ramesar et al [9] in adult Wistar rats, while that obtained in the SHR corroborates previous results in SHRs [11,12] and Dahl salt sensitive rats $[8,10,15]$.

The mechanisms implicated in the pathogenesis of CVD include alterations in the renin angiotensin aldosterone system (RAAS) [2], the autonomic nervous system [2,24], the reactive oxygen species [25], and thrombosis [25]. Similarly, $T$. violacea has been reported to inhibit ACE $[9,11]$ and the expression of AT1a mRNA [8]; reduce aldosterone levels in plasma [12], and consequently increase diuresis and natriuresis $[8,10]$ in rats. It has also been found to stimulate the muscarinic receptors [12], block $\beta 1$ adrenoceptors [12], and improve antioxidant activity [6]. Although the specific mechanisms by which $T$. violacea reduced $\mathrm{BP}$ and $\mathrm{HR}$ in the ageing WKY and SHR were not investigated in the current study, we propose that some of the mechanism previously mentioned, with other rats of different ages and genetic make-up [6,812,15], would have contributed to the antihypertensive effect observed. 


\section{CONCLUSION}

Crude MLE of $T$. violacea reduces $B P$ and $H R$ in ageing normotensive WKY rats and in adult spontaneously hypertensive rats. No significant differences were observed with the BP and HRlowering effect, despite the differences in the pathology of high blood pressure in the two strains used. Thus, $T$. violacea may not only be able to reduce $\mathrm{BP}$ and $\mathrm{HR}$ in rats, but may also be useful in the management of HTN in both young and elderly patients.

\section{DECLARATIONS}

\section{Acknowledgement}

The authors will like to appreciate the assistance of Mr Vinesh Jeavan for his technical inputs, and the University of the Western Cape for financial support of the study.

\section{Conflict of Interest}

No conflict of interest associated with this work.

\section{Contribution of Authors}

The authors declare that this work was done by the authors named in this article and all liabilities pertaining to claims relating to the content of this article will be borne by them.

\section{Open Access}

This is an Open Access article distributed under the terms of the Creative Commons Attribution License, which permits unrestricted use, distribution, and reproduction in any medium, provided the original work is properly credited.

\section{REFERENCES}

1. Xie $X$, Atkins $E, L v J$, Bennett $A$, Neal B, Ninomiya $T$, Woodward M, MacMahon S, Turnbull F, Hillis GS, et al. Effects of intensive blood pressure lowering on cardiovascular and renal outcomes: updated systematic review and meta-analysis. Lancet 2016; 387(10017): 435-443.

2. Thomopoulos C, Parati G, Zanchetti A. Effects of blood pressure lowering on outcome incidence in hypertension: 4. Effects of various classes of antihypertensive drugs--overview and meta-analyses. J Hypertens 2015; 33(2): 195-211.

3. Vega J, Bisognano JD. The prevalence, incidence, prognosis, and associated conditions of resistant hypertension. Semin Nephrol 2014; 34(3): 247-256.
4. Modesti PA, Perruolo E, Parati G. Need for better blood pressure measurement in developing countries to improve prevention of cardiovascular disease. $J$ Epidemiol 2015; 25(2): 91-98.

5. Oliva RV, Bakris GL. Management of hypertension in the elderly population. J Gerontol Series A: Biol Sci Med Sci 2012; 67(12): 1343-1351.

6. Moodley K, Joseph K, Naidoo Y, Islam S, Mackraj I. Antioxidant, antidiabetic and hypolipidemic effects of Tulbaghia violacea Harv. (wild garlic) rhizome methanolic extract in a diabetic rat model. BMC complementary and alternative medicine 2015; 15(1):1.

7. Bungu L, van de Venter M, Frost C. Evidence for an in vitro anticoagulant and antithrombotic activity in Tulbaghia violacea. Afr J Biotechnol 2008; 7(6): 681688.

8. Mackraj I, Ramesar S, Singh M, Govender T, Baijnath H, Singh $R$, Gathiram $P$. The in vivo effects of Tulbhagia violacea on blood pressure in a salt-sensitive rat model. J Ethnopharmacol 2008; 117(2): 263-269.

9. Ramesar S, Baijnath $H$, Govender $T$, Mackraj I. Angiotensin l-converting enzyme inhibitor activity of nutritive plants in KwaZulu-Natal. J Medicin food 2008; 11(2): 331-336.

10. Moodley K, Mackraj I, Naidoo Y. Cardiovascular effects of Tulbaghia violacea Harv. (Alliaceae) root methanolic extract in Dahl salt-sensitive (DSS) rats. J Ethnopharmacol 2013; 146(1): 225-231.

11. Raji IA, Mugabo P, Obikeze K. Effect of Tulbaghia violacea on the blood pressure and heart rate in male spontaneously hypertensive Wistar rats. J Ethnopharmacol 2012; 140(1): 98-106.

12. Raji I, Mugabo $P$, Obikeze $K$. The contributions of muscarinic receptors and changes in plasma aldosterone levels to the anti-hypertensive effect of Tulbaghia violacea. BMC Complement Altern Med 2013; 13(1): 13.

13. White WB, Gulati V. Managing hypertension with ambulatory blood pressure monitoring. Curr Cardiol Rep 2015; 17(2): 2.

14. Canavan $M$, Smyth A, Bosch J, Jensen M, McGrath ER, Mulkerrin EC, O'Donnell MJ. Does lowering blood pressure with antihypertensive therapy preserve independence in activities of daily living? A systematic review. Am J Hypertens 2015; 28(2): 273-279.

15. Moodley K, Naidoo Y, Mackraj I. Effects of Tulbaghia violacea Harv. (Alliaceae) rhizome methanolic extract on kidney function and morphology in Dahl salt-sensitive rats. J Ethnopharmacol 2014; 155(2): 1194-1203.

16. Gilad GM, Gilad VH. Age-related reductions in brain cholinergic and dopaminergic indices in two rat strains differing in longevity. Brain Res 1987; 408(1): 247-250.

17. Doggrell SA, Brown L. Rat models of hypertension, cardiac hypertrophy and failure. Cardiovasc Res 1998; 39(1): 89-105.

18. Scridon A, Fouilloux-Meugnier E, Loizon E, Perian M, Rome $S$, Julien $C$, Barrès $C$, Chevalier $P$. Agedependent myocardial transcriptomic changes in the rat.

Trop J Pharm Res, November 2016; 15(11): 2433 
Novel insights into atrial and ventricular arrhythmias pathogenesis. Romanian Rev Lab Med 2014; 22(1): 923.

19. Lišková S, Petrová M, Karen P, Kuneš J, Zicha J. Effects of aging and hypertension on the participation of endothelium-derived constricting factor (EDCF) in norepinephrine-induced contraction of rat femoral artery. Eur J Pharmacol 2011; 667(1-3): 265-270.

20. Sengupta $P$. The laboratory rat: relating its age with humans. Int J Prev Med 2013; 4(6): 624.

21. Andreollo NA, Santos EF, Araujo MR, Lopes LR. Rat's age versus human's age: what is the relationship? Arq Bras Cir Dig 2012; 25(1):49-51.

22. Valenti VE, Ferreira $C$, Meneghini A, Ferreira $M$, Murad N, Ferreira Filho C, Correa JA, Abreu LC, Colombari E.
Evaluation of baroreflex function in young spontaneously hypertensive rats. Arquivos Brasileiros de Cardiologia 2009; 92(3):216-221.

23. Goto K, Fujii K, Kansui $Y$, lida $M$. Changes in endothelium-derived hyperpolarizing factor in hypertension and ageing: response to chronic treatment with renin-angiotensin system inhibitors. Clin Exp Pharmacol Physiol 2004; 31(9):650-655.

24. Farquhar WB, Edwards DG, Jurkovitz CT, Weintraub WS. Dietary sodium and health: more than just blood pressure. J Am Coll Cardiol 2015; 65(10):1042-1050.

25. Juni RP, Duckers HJ, Vanhoutte PM, Virmani R, Moens AL. Oxidative Stress and Pathological Changes After Coronary Artery Interventions. Journal of the American College of Cardiology 2013; 61(14):1471-1481. 